\title{
Erratum to: High frequency of infection with tuberculosis as the most common cause of bone marrow necrosis: a study from tertiary care centre in northern India and their clinico-pathologic analysis
}

Prabhu Manivannan ${ }^{1} \cdot$ Abhishek Purohit $^{1} \cdot$ Mukul Aggarwal $^{1}$.

Venkatesan Somasundaram $^{1}$ • Ankur Ahuja ${ }^{1} \cdot$ Renu Saxena $^{1}$

Published online: 23 June 2015

(C) Springer-Verlag Berlin Heidelberg 2015

Erratum to: J Hematopathol

DOI 10.1007/s12308-015-0244-5

The original version of this article unfortunately inadvertently deleted the other authors which is now corrected in the authorgroup of this article.

The online version of the original article can be found at http://dx.doi.org/ 10.1007/s12308-015-0244-5.

$\triangle$ Abhishek Purohit

purohitabhi80@gmail.com

All India Institute of Medical Sciences (AIIMS), Ansari Nagar New

Delhi 110068, India 